\title{
Some Studies of Atmospheric Transmittance on Mauna Loa
}

\author{
Ralph Stair and Russell G. Johnston
}

\begin{abstract}
Studies are described of the spectral intensity of solar radiation and its transmission through the atmosphere above a new 11,140-foot-altitude station on Mauna Loa, Hawaii, during May and June 1957. The spectral measurements covered the region from 300 millimicrons to 2.5 microns for different air masses from about 3.0 to 1.0. The amounts of ozone and of water vapor which were present in the upper atmosphere were calculated from spectral data obtained on several different days.
\end{abstract}

\section{Introduction}

During the past few years measurements on the spectral distribution of the radiant energy from the sun have been carried out at locations in Colorado and New Mexico [1-3] ${ }^{1}$ because of high altitude and great distance from commercial activities. However, in each case there was a considerable amount of interference resulting from the presence of relatively great amounts of dust or water vapor much of the time. To get away from conditions of this type it was proposed that a station be set up at a high altitude in the Hawaiian Islands for this work.

Although few weather data were available for high altitude locations in the Hawaiian Islands, such data as existed indicated the superiority of a location on the north slope of Mauna Loa, on the island of Hawaii, for use in solar radiation and atmospheric transmission studies such as were being made. Furthermore, the available data and information indicated that an observing station situated at an altitude above $11,000 \mathrm{ft}$ on this mountain would be above the normal atmospheric inversion layer much of the time and hence above most of the atmospheric dust and water vapor. Furthermore there are but few urban or rural land areas nearby to produce city and country air-pollution products.

For many years the U. S. Weather Bureau had been interested in a high altitude weather observing station on Mauna Loa. The first positive action in this direction occurred in 1951 when, through the efforts of various persons and agencies, a small shelter was erected at an altitude of approximately $13,450 \mathrm{ft}$ near the Mokuaweoweo crater at the summit of Mauna Loa. As this location was difficult of access because of a rough lava terrain and the absence of an improved roadway it became advisable to establish the Mauna Loa Observatory at the terminus of the existing road just above $11,000 \mathrm{ft}$ (at approximately $11,140 \mathrm{ft}$ ). This altitude has a further advantage over that of the summit location in affording conditions of atmospheric pressure (and hence oxygen concentration) more in keeping with the normal requirements of the average individual. Many observers would be unable to live and work at a much higher level.

Late in 1955 arrangements were set up between the U. S. Weather Bureau and the National Bureau

1 Figure in brackets indicate the literature references at the end of this paper. of Standards for the latter institution to establish an observing station (with funds supplied by the U. S. Weather Bureau) on Mauna Loa, for the joint use of the two laboratories. Accordingly, through contacts with the Territorial Government of Hawaii a small parcel of land (4.05 acres) on the north slope of Mauna Loa, the land marker being set at an altitude of $11,134 \mathrm{ft}$, was transferred back to the Federal Government (Department of Commerce) and the Mauna Loa Observatory was constructed by the National Bureau of Standards during the early part of 1956.

Since this is a new station and location for spectral solar radiant energy measurements a few comments relating to the building and its facilities are in order. The main section of the Observatory (see figs. 1 and 2) consists of a one-story concrete block building (20 by $40 \mathrm{ft}$ ) partitioned into a 16 - by 20 -ft laboratory, three bedrooms, and a kitchenette, all furnished for pleasant and comfortable living and working quarters for six observers. A concrete platform (15 by $45 \mathrm{ft}$ ) on the south side, and a tower ( 8 by $8 \mathrm{ft}$ ) at the east end of the building, provide space for solar radiation measurements and for other experiments requiring outside exposures. Electrical power for the laboratory and housing facilities is provided by diesel-electric generators at $110 \mathrm{v}, 60$ cps single phase. Water is provided through a roof catchment, storage, and distribution system, while the fuel for the heating, cooking, and refrigeration is provided through the use of butane from tanks. A radio

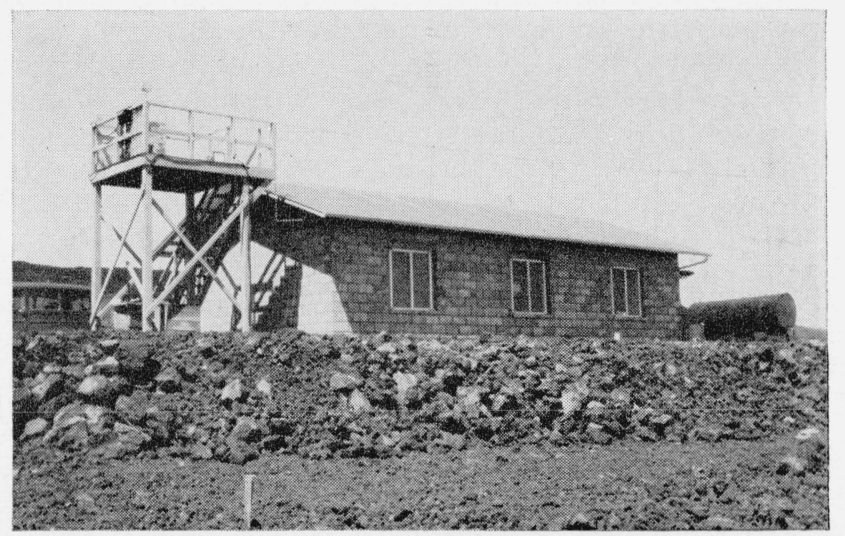

Figure 1. Mauna Loa Observatory; altitude 11,140 ft, looking southwest. 




Figure 2. Instrumental setup on outside platform in front of Mauna Loa Observatory.

transmitter and receiver linked with a similar station at the U. S. Weather Bureau in Hilo furnishes continuous two-way contact with the outside world. A small library, supplemented by $\mathrm{TV}$ and radio broadcasts help in furnishing recreation at evenings and during bad weather. Other data about the Mauna Loa Observatory have been published elsewhere [4].

The observatory is reached by a cinder road, built and kept in repair by the Department of Institutions, Territory of Hawaii, and extending a distance of about 45 miles from near Hilo to just above the location of the observatory. Through most of the distance up the mountain the grade is gradual so that a stock automobile (having high clearance) can maneuver the $11,000-\mathrm{ft}$ climb in less than $2 \mathrm{hr}$. It is, however, recommended that a 4-wheel-drive, highslung vehicle be employed for general use in this area.

In the following paragraphs the spectroradiometric setup is briefly described and some results are given on atmospheric scattering and the amounts of ozone and water vapor above Mauna Loa on several days in May and June 1957, as deduced from measurements of solar spectral radiant energy.

\section{Instruments and Method}

The instrumental setup (see fig. 2) was essentially the same as employed at Sunspot, N. Mex., in 1955 [3]. New PbS cells (and associated housings and electronies) having higher sensitivities and less noise were employed in the present case. A further improvement was obtained by operating the $\mathrm{PbS}$ cells at lower temperatures (the ambient air temperature) rather than at a controlled elevated temperature as was the case in 1955 . As a result the infrared data could be repeated more closely from time to time during each day with only small sensitivity drifts as the air temperature slowly changed. A type-935 phototube was employed in the ultraviolet spectral measurements.

An additional instrument for obtaining a measure of the amount of sky scattering was incorporated into the equipment. This consisted of a photoelectric photometer for comparative brightness measure- ment of the sun and an area of the sky nearby and surrounding the sun. Readings were alternately taken for the intensity of the solar disk and for that of an arbitrary area of the sky consisting of an annular ring of a few degrees immediately surrounding the sun. In each case the radiant energy was confined essentially to a narrow band in the yellow-green region of the visible spectrum through the use of a yellow-green filter (a dark-shade welding glass).

The electronics of the instrument for the measurement of sky scattering were arranged so that the same tuned amplifier and recorder could be readily shifted from the output of the spectroradiometer phototube to that of the auxiliary instrument without disrupting the recorder time scale. Thus the two records appeared on the same chart in proper sequence. Calibration was accomplished through an on-the-spot comparison with an Evans [5] visual photometer. Thus the portrayed data are given in terms of sky brightness within an annular conical angle near the sun relative to that of the solar disk

The use of electrical power from a small dieselelectric generating plant caused a number of problems in the practical operation of the equipment. First, it is very difficult to keep a small diesel-electric generating plant (in this case a 5 -kw unit) in continuous operation at precisely $60 \mathrm{cps}$ with the voltage constant, especially at this altitude and with considerable variation in the load. The power requirements of all other station activities were dependent upon the same power source. Furthermore, the need for regular servicing of the equipment required the alternate use of two similar units, which usually varied in output voltage and frequency. Because these difficulties had been anticipated previous to the setting up of the equipment, crystal-controlled electronic power supplies had been procured to handle the power requirements of all motors and amplifiers of the setup in which either voltage or frequency changes might result in erratic operation. Greatly improved operation resulted through the use of the crystal-controlled electronic power units. However, there remains no question but that commercial power would be preferred. Hence, a real need at the Mauna Loa Observatory is an extension of power lines for the remaining 12 miles up the mountain to the observatory.

In addition to the equipment employed in the spectral radiant-energy and sky-scattering measurements the standard U. S. Weather Bureau station instruments were available and were regularly read and the data transmitted to the Hilo office, and incidentally employed in the evaluation of the surfacehumidity values reported herein.

\section{Spectral Solar-Energy Distribution}

On those days when the sky was clear, during a period of about 8 weeks in May and June 1957, spectral data were obtained either through the shorter-wavelength region, 300 to $550 \mathrm{~m} \mu$, by using a 935-type photoemission tube, or else through the longer-wavelength region, about $330 \mathrm{~m} \mu$ to $2.5 \mu$, by using a $\mathrm{PbS}$ cell. These data were evaluated in 
a manner similar to that previously followed and were found to be in general agreement with the earlier data [3] both as to spectral quality and absolute magnitude, except that they show a higher degree of scattering as a result of difficulties in keeping the power supply constant, or as the result of changes in atmospheric humidity.

\section{Atmospheric Transmittance and Ozone}

Following the same procedures as employed in previous work [1-3] the atmospheric transmission curve for the atmosphere above Mauna Loa (see figs. 3 and 4) was determined on the basis of two sets of ozone transmission coefficients - those of Fabry and Buisson [6], and those of Vigroux [7]for the average data for 4 days in May (May 21, 28,29 , and 30 ).

In figure 3 the Fabry and Buisson ozone transmission coefficients were employed in the calculation of the two curves representing the amounts of ozone required for a specific amount of optical absorption. On the basis of these data, about $0.24 \mathrm{~cm}$ of ozone (ntp) was present above Mauna Loa at the time of

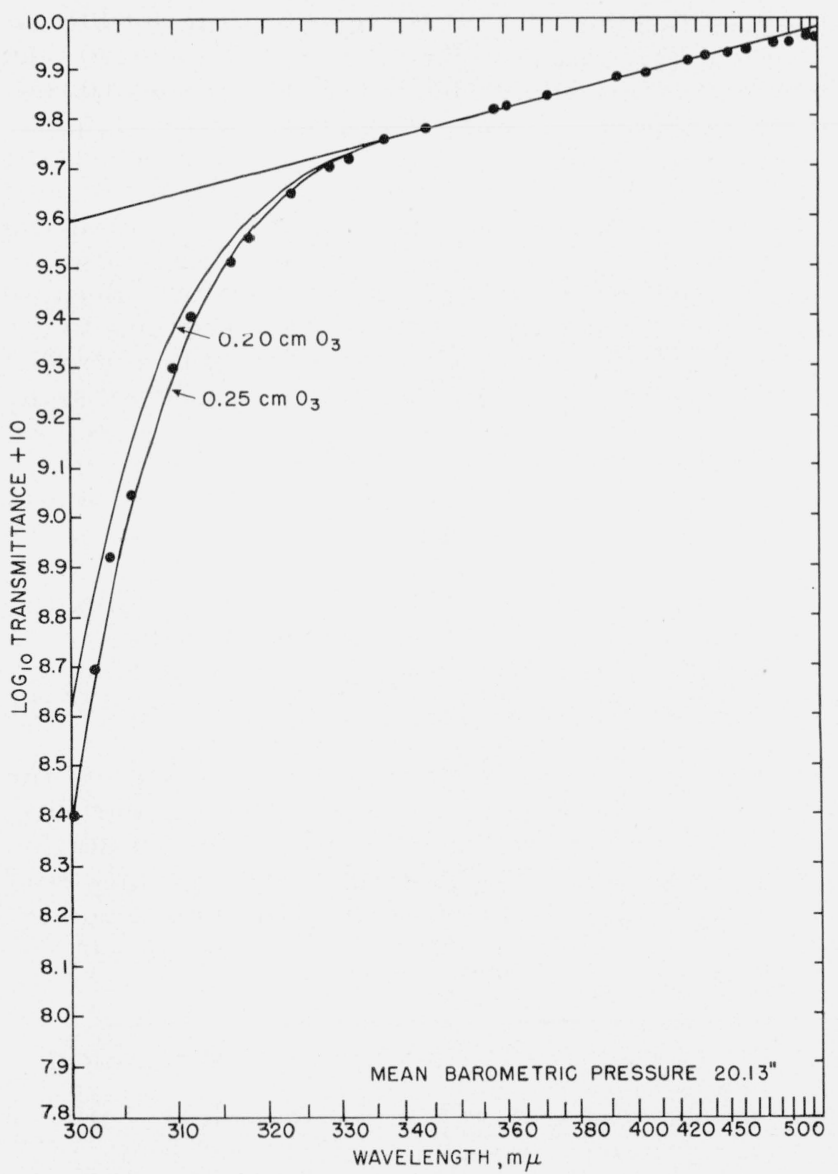

Figure 3. Atmospheric transmittance above Mauna Loa Observatory, altitude 11,140 ft; also determination of total ozone using Fabry and Buisson transmission coefficients.

Upper curve, scattering; lower curves, ozone; circles, measured atmospheric transmittance; air mass, 1.00; wavelength scale expanded as a function of $-(n-1)^{2} \lambda^{-4}$.

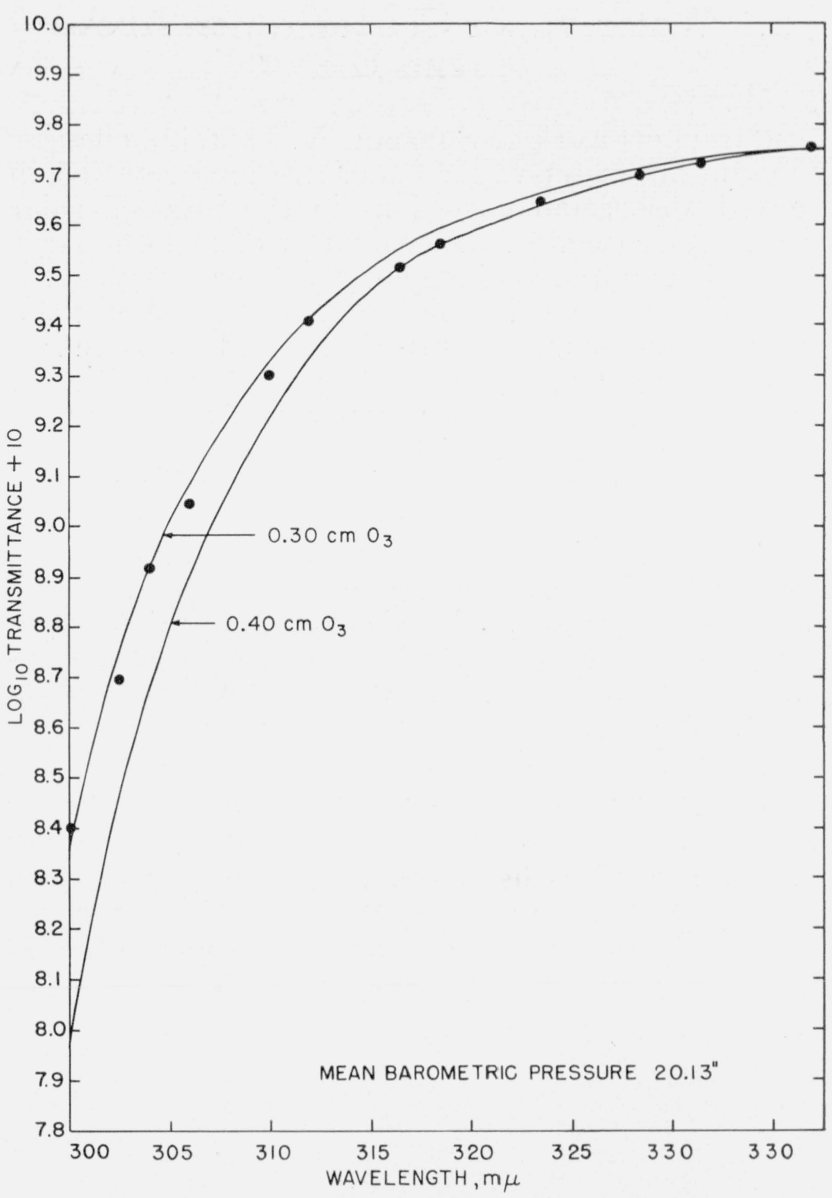

Figure 4. Atmospheric transmittance above Mauna LoaTObservatory, altitude 11,140 ft; also determination of total ozone using Vigroux transmission coefficients.

Circles, measured atmospheric transmittance; air mass, 1.00 .

the measurements. This value is in close agreement with the results of previous measurements of high altitude ozone at Climax, Colo. [1], and at Sunspot, N. Mex. [2, 3].

In figure 4 the same experimental data (for wavelengths shorter than about $337 \mathrm{~m} \mu$ ) are replotted, this time along with ozone curves calculated on the basis of Vigroux's transmission coefficients. New data by Inn and Tanaka [23] agree closely with those of Vigroux within the spectral region of 300 to 350 $\mathrm{m} \mu$. It is to be noted on the basis of these data that the calculated amount of ozone (ntp) becomes about $0.32 \mathrm{~cm}$. Furthermore, if the data obtained at Climax and Sunspot are evaluated in terms of Vigroux's coefficients of ozone absorption, then the previously published ozone values should be increased to about $0.30 \mathrm{~cm}$. Since the calculated value of atmospheric ozone depends upon the laboratory measurements of the absorption coefficients of ozone, and since there is considerable spread between the values obtained through using the two sets of data, it seems advisable to report both values until further experiment definitely determines the absorption coefficients of ozone. 


\section{Water Vapor Concentration Above Mauna Loa}

In previous work at Sunspot, N. Mex. [2], changes in upper-air water-vapor concentrations resulted in marked absorption variations in the infrared solar spectrum (see fig. 5). As a matter of fact the large fluctuations noted at Sunspot were a primary reason for seeking the new location on Mauna Loa where a lower water-vapor concentration would interfere less with the measurement of the spectral intensities in the infrared. But water vapor is such a highly absorbing constituent of the atmosphere that even at the very low concentrations ordinarily present above Mauna Loa there is still a marked absorption within the principal water-vapor bands, even near noon on days having a relatively low total watervapor concentration. Then small changes in water vapor produce large changes in total optical absorption within the regions of the principal absorption bands.

The spectroscopic method of evaluating the amount of the water vapor was originated by Fowle nearly a half century ago [8-11]. However, its use in routine studies has been greatly neglected until recent years when the U. S. Weather Bureau [12-17] and others $[18,19]$ have set up various types of hygrometers, filter radiometers, and spectroradiometers for water-vapor studies.
It should be noted that the water-vapor molecule has three principal modes of vibration resulting in three primary absorption bands located at $2.66,2.74$ and $6.26 \mu[20]$. The resulting combinations and overtones are responsible for the production of many bands (of lesser absorption) extending to shorter wavelengths. Principally among these are the bands centered at $0.942,1.135,1.370$, and $1.872 \mu$, which increase in intensity of absorption with wavelength. Each of these bands produces a marked amount of optical absorption in the solar spectrum.

The relationship between the apparent absorption of water vapor (as measured with a prism instrument) and the amount of the vapor is not a simple one since each absorption band really consists of many fine lines of uneven intensity irregularly spaced. Furthermore, the attenuation at any wavelength due to water vapor is a complicated function of the pressure, temperature, and concentration of the vapor per unit volume. But the presence of all these complications does not prevent the use of the absorptionspectra method through the adoption of an empirical relationship between the optical absorption and the absolute amount of water in the atmosphere.

The spectroradiometric method for determining the water-vapor concentration in the upper atmosphere is rapid and practical for routine work-so long as the sun is not clouded over. It remains the most applicable of some $\mathbf{1 5}$ methods of water-vapor or moisture evaluation recently described [21]. This

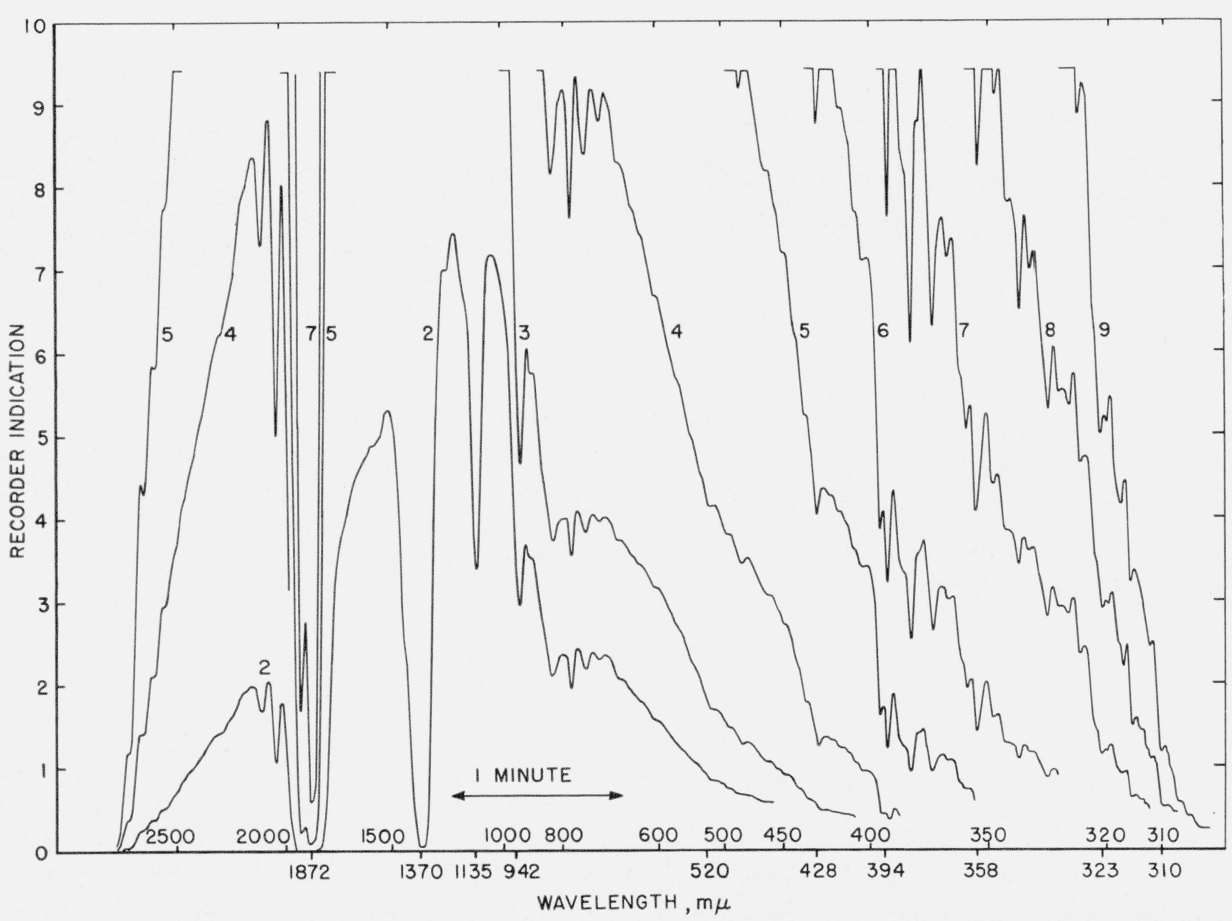

FIGURE 5. Representative data taken from a section of the recorder chart while employing $a^{\top} P b S$ cell as a detector at Sunspot, New Mexico, in 1953.

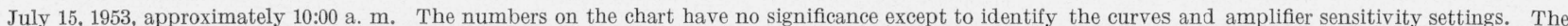

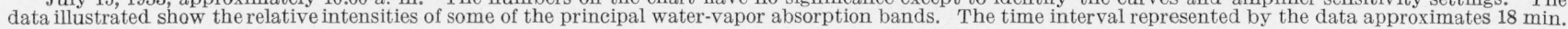


method, as developed by Fowle, permits calibration either in terms of total band absorption or of absorption at a single wavelength. In practice a combination of the two (the depth of a prismatic band) is simpler and has been found to yield more consistent results $[10,18]$ when a prism spectroradiometer is employed.

Any one of the water-vapor bands may be chosen for use in determining the total amount of precipitable water above the observer. In the present case, as noted above, the available bands for this purpose are located at $0.94,1.135,1.370$, and $1.872 \mu$. (See figs. 5 and 6 which are representative of field data obtained at Sunspot, N. Mex. and on Mauna Loa, respectively.) It is important for highest accuracy to choose that band which is located in the part of the spectrum where the recorded intensities of solar spectral radiant energy are such that, in combination with the response properties of the spectroradiometer employed, a nearly horizontal curve results when the envelope of the recorder trace is drawn. Furthermore, greater sensitivity in detecting changes in the water-vapor content of the upper atmosphere can be obtained if the maximum of absorption falls between 25 and 75 percent. In the present case the band at $1.135 \mu$ best meets these requirements. Hence this band has been chosen for use in evaluating the precipitable water above Mauna Loa.

Although the spectroradiometric method is rapid and highly practicable, its use entails certain assumptions relating to the characteristics of the shapes of the water-vapor absorption bands as affected by such things in the environment and instrument design as temperature, pressure, slit width, etc., which may and have been studied in the laboratory $[8,10$, 11, 19], and their effects evaluated. Principal among these in importance is instrumental slit width or spectral purity. Fowle [10] determined a calibration employing specific slit widths through the use of a spectrobolometer by observing the depths of the water bands resulting from the absorption of a known amount of water vapor in a long tube. He furthermore determined that under the usual conditions of temperature and pressure of the upper atmosphere that in the practical case their effects could be neglected. This calibration of the total precipitable water in centimeters is given in figure 7 in terms of the intensity ratio for the water-vapor band at 1.135 $\mu$ when the spectral purity (slit width in wavelength) was $0.04 \mu$, as employed in the Mauna Loa work. We have used this calibration in the evaluation of the Mauna Loa data.

While this calibration and its application to the field data may not be of the highest accuracy owing to some question as to the total width of the band and its resultant effect upon depth measurements of the center of the band, it appears that the resulting errors are small since they would appear in a similar manner in both the field and laboratory data and would thus for the greater part cancel out.

The data for 4 days (June 7, 8, 12, and 13) have been analyzed and the amounts of precipitable water above the station plotted in figures 8 to 11, inclusive,

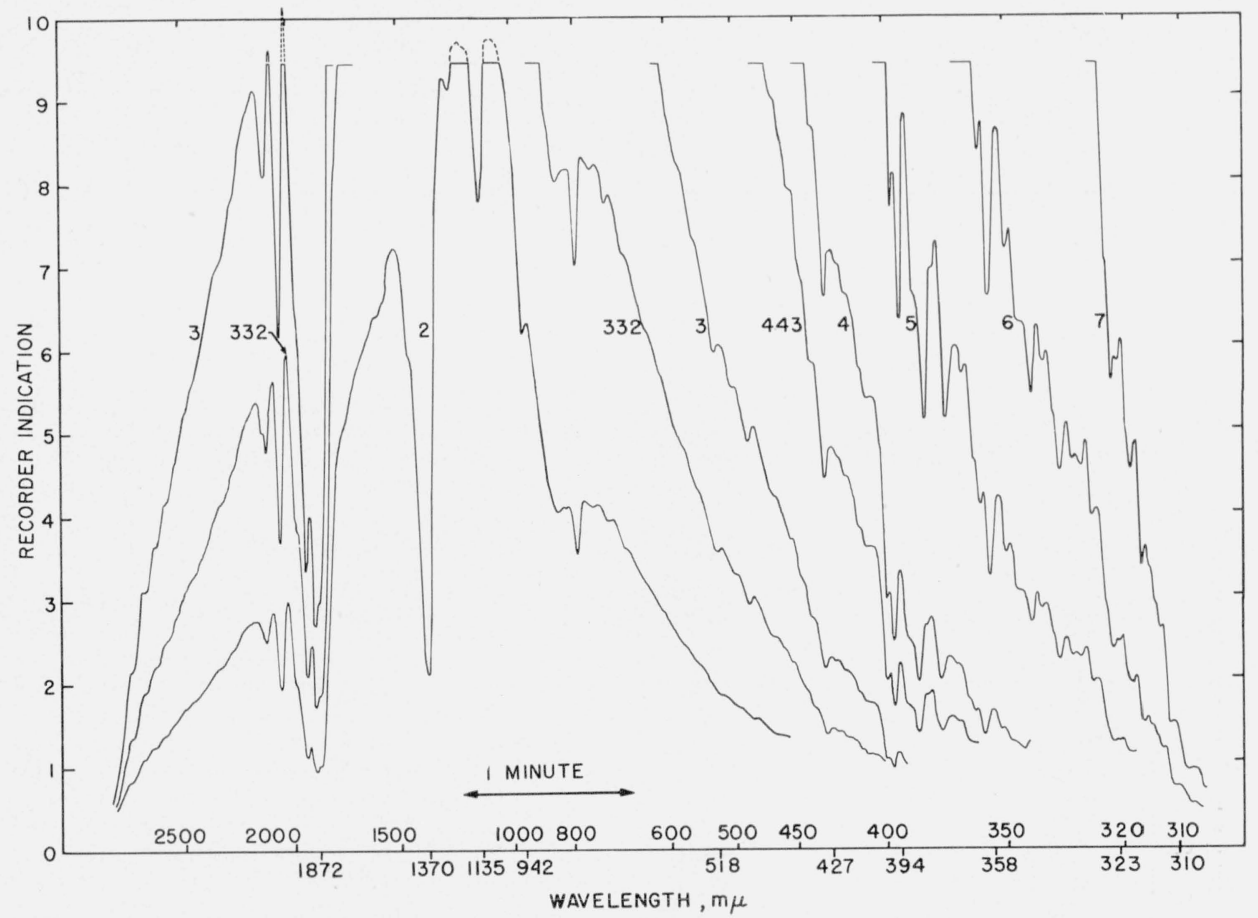

Figure 6. Representative data taken from a section of the recorder chart while employing a PbS cell as a detector at Mauna Loa in $195 \%$.

June 12,1957, approximately 10:00 a. m. The numbers on the chart have no significance except to identify the curves and amplifier sensitivity settings.

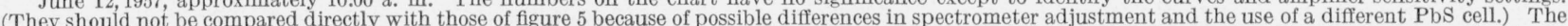

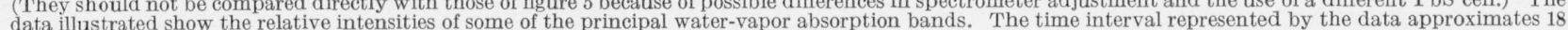
min. 


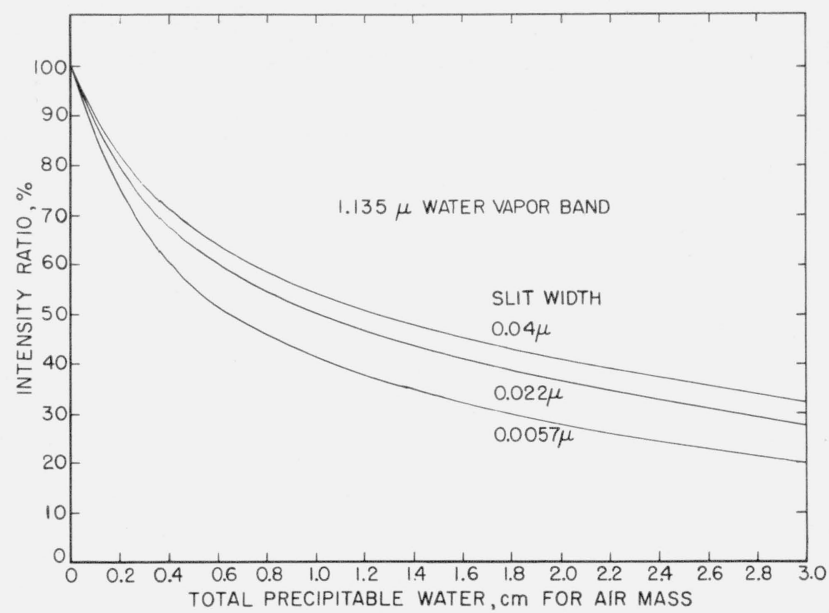

FIGURE 7. Intensity ratios of radiation at the center of the $1.135 \mu$ water-vapor band as a function of total precipitable water in the atmosphere for a prism instrument having specific spectral purity (effective slit widths).

Data from Fowle, reference 10.

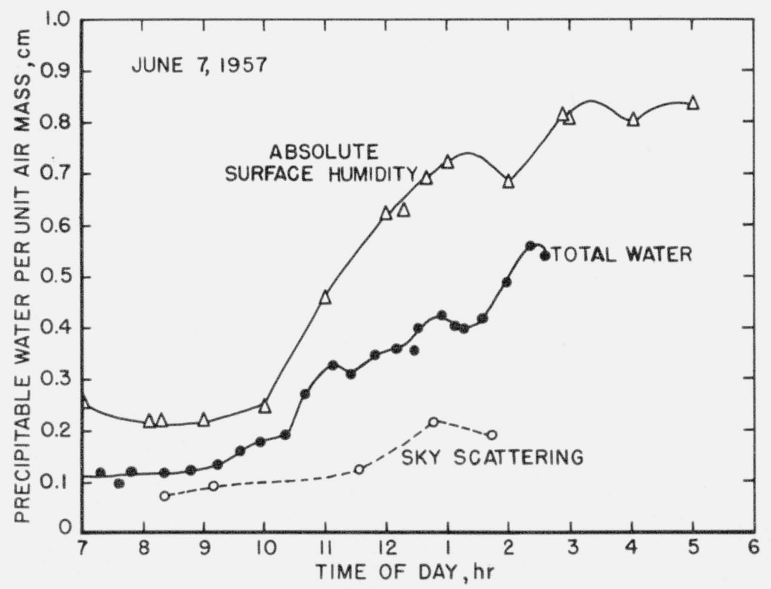

FIGURE 8. Precipitable water in centimeters on June $7,195 \%$, for air mass 1.00 over Mauna Loa Observatory from spectroradiometric measurements in the spectral region of $1.135 \mu$; also on a relative scale are absolute surface humidity, and sky scattering near the solar disk reduced to air mass 1.00

Barometric pressure 20.16 in. Hawaiian Standard Time.

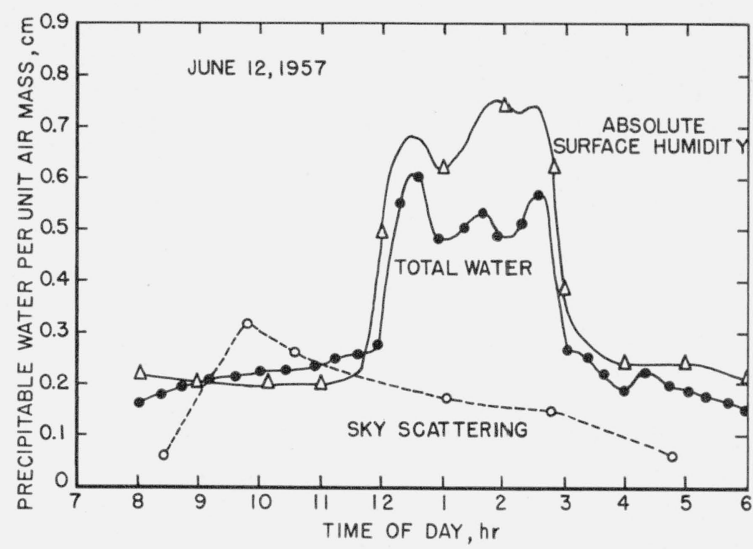

Figure 10. Precipitable water in centimeters on June 12, 195\%, for air mass 1.00 over the Mauna Loa Observatory from spectroradiometric measurements in the spectral region of $1.135 \mu$; also on a relative scale are absolute surface humidity, and sky scattering near the solar disk reduced to air mass 1.00 .

Barometric pressure 20.23 in. Hawaiian Standard Time.

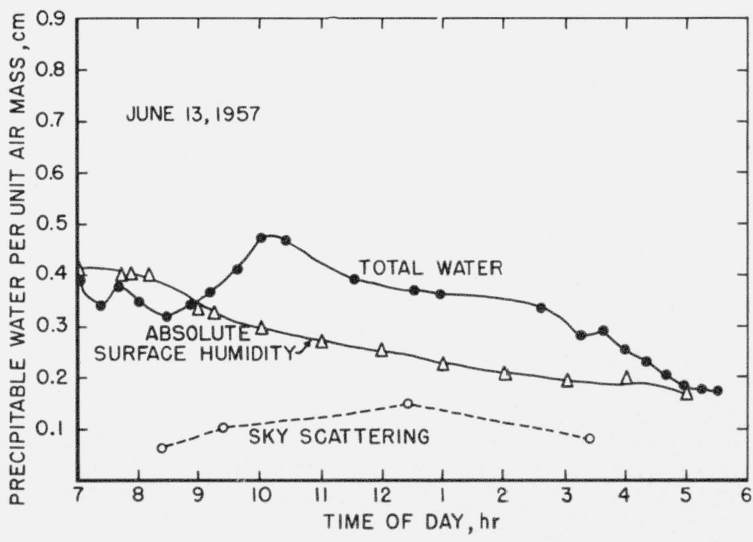

Figure 11. Precipitable water in centimeters on June 13 195\%, for air mass 1.00 over the Mauna Loa Observatory from spectroradiometric measurements in the spectral region of $1.35 \mu$; also on a relative scale are absolute surface humidity, and sky scattering near the solar disk reduced to air mass 1.00 . Barometric pressure 20.23 in. Hawaiian Standard Time.

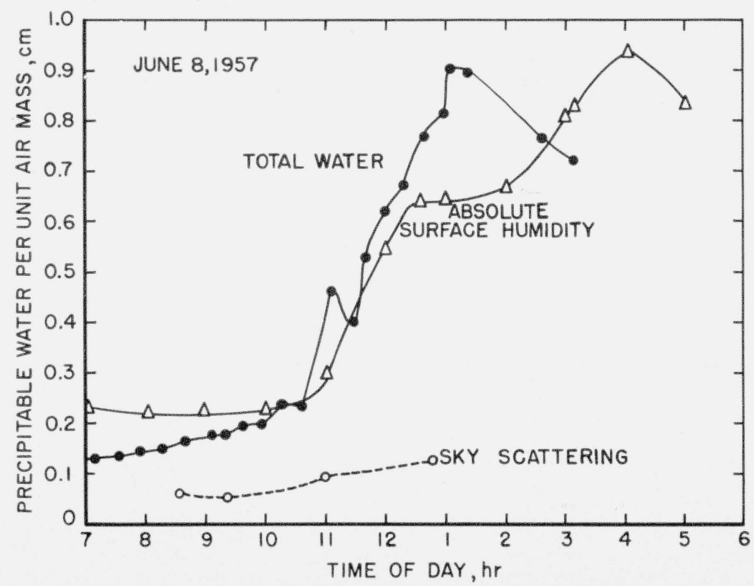

Figure 9. Precipitable water in centimeters on June 8, 195\%, for air mass 1.00 over the Mauna Loa.Observatory from spectroradiometric measurements in the spectral region of $1.135 \mu$; also on a relative scale are absolute surface humidity, and sky scattering near the solar disk reduced to air mass 1.00 .

Barometric pressure 20.16 in. Hawaiian Standard Time. 
as a function of the time of day. On these same plots are illustrated the relative amounts of precipitable water (absolute surface humidity) based on measurements of relative humidity and temperature at the station. These data are necessarily on a relative scale (but the same relative scale for the 4 days) as no means were available for determining the water at higher altitudes by this method. It is significant that on any one day there is a general correlation between the water-measurements at the station and the total amount of water as integrated for all altitudes by the spectroradiometric method. This probably indicates that the major part of the water above the station is near the station level.

A study of figures 8 to 11 , coupled with the general observations of the sky at the station over a period of several months and with the experience of other observers in Martian studies [22] at this station, signifies that as a general rule there is a very low water concentration above Mauna Loa from late afternoon until late in the morning of the next day. Under certain weather conditions the low water concentration continues undisturbed throughout the 24-hr period. On many days, however, the inversion layer is disrupted near noon or in early afternoon thus allowing a mass of humid atmosphere to sweep up the mountain and enshroud the station either temporarily for an hour or two or until late afternoon or early evening. Except during unfavorable weather, however, the mass of humid atmosphere again descends the mountain during the late afternoon or early evening so that a picturesque sunset may be viewed-and on especially favorable occasions in such a way that the brilliant "green flash" may be observed immediately following the disappearance of the edge of the sun from view.

The amount of atmospheric scattering in the visible spectrum as measured in the annular conical angle surrounding the sun (figs. 8 to 11 , inclusive) seems to have no definite relationship to the total precipitable water above the station. This is interesting and indicates the importance of additional study of atmospheric transmittance and scattering at high altitudes. It was noted that the sky appeared less blue when there was a minimum amount of water present; also that the sky usually appeared much bluer when viewed at the 5000- to $8000-\mathrm{ft}$ levels than when viewed from the altitude of the Mauna Loa Observatory (11,140 ft).

The authors express their sincere appreciation to the Geophysics Research Directorate of Air Force Cambridge Research Center and the U. S. Weather Bureau for supporting this project, and to individual members of those organizations, in particular to P. R. Gast for helpful advice and assistance, and to R. G. Busniewski for much assistance in connection with the operation of the radio linkage and carrying out the field work at the observatory.

\section{References}

[1] Ralph Stair, Ultraviolet radiant energy from the sun observed at 11,190 feet, J. Research NBS 49, 227 (1952) RP2357.

[2] Ralph Stair, Russell G. Johnston, and Thomas C. Bragg, Spectral distribution of energy from the sun, J. Research NBS 53, 113 (1954) RP2523.

[3] Ralph Stair and Russell G. Johnston, Preliminary spectroradiometric measurements of the solar constant, J. Research NBS 5\%, 205 (1956) RP2710.

[4] Roy L. Fox, New Mauna Loa Observatory unit, Nature 178, 1272 (1956).

[5] John W. Evans, A photometer for measurement of sky brightness near the sun, J. Opt. Soc. Am. 38, 1083 (1948).

[6] C. Fabry and H. Buisson, Data on ozone absorption, Compt. rend. 192, 457 (1931).

[7] E. Vigroux, Contributions a l'étude expérimentale de l'absorption de l'ozone, Ann. phys. 8, 709 (1953).

[8] F. E. Fowle, The spectroscopic determination of aqueous vapor, Astrophys. J. 35, 149 (1912).

[9] F. E. Fowle, The determination of aqueous vapor above Mount Wilson, Astrophys. J. 37, 359 (1913).

[10] F. E. Fowle, The transparency of aqueous vapor, Astrophys. J. 42, 394 (1915).

[11] L. B. Aldrich, Note on Fowle's spectrographic method for the determination of aqueous vapor in the atmosphere, Smith. Misc. Collections 111, No. 12, p. 1 (1949).

[12] L. W. Foskett and N. B. Foster, A spectroscopic hygrometer, Bull. Am. Meteorol. Soc. 24, 146 (1943).

[13] Norman B. Foster and Laurence W. Foskett, A spectrophotometer for the determination of the water vapor in a vertical column of the atmosphere, J. Opt. Soc. Am. 35, 601 (1945).

[14] L. W. Foskett, N. B. Foster, W. R. Thickstun, and R. C. Wood, Infrared absorption hygrometer, Monthly Weather Rev. 81, 267 (1953).

[15] S. B. Solot, Computation of depth of precipitable water in a column of air, Monthly Weather Rev. 6\%, 100 (1939).

[16] W. M. Elsasser, New values for infrared absorption coefficient of atmospheric water vapor, Monthly Weather Rev. 66, 175 (1938).

[17] David S. Johnson, Field test of a total equivalent precipitable water hygrometer, Unpublished manuscript of the U. S. Weather Bureau.

[18] David M. Gates, Infrared determination of precipitable water vapor in a vertical column of the earth's atmosphere, J. Meteorol. 13, 369 (1956).

[19] J. N. Howard, D. E. Burch, and D. Williams, Near infrared transmission through synthetic atmospheres, Geophysical Res. Pap., No. 40, G. R. D., AFCRC, ÁRDC (1955), ASTIA document No. AD-87679.

[20] E. K. Plyler and W. W. Sleator, Further study of the absorption of infrared radiation by water vapor, Phys. Rev., 2d Series 37, 1493 (1931).

[21] Arnold Wexler and W. G. Brombacher, Methods of measuring humidity and testing hygrometers, NBS Circ. 512 (1951).

[22] C. C. Kiess, C. H. Corliss, Harriet K. Kiess, and Edith L. R. Corliss, High-dispersion spectra of Mars, Astrophys. J. 126, 579 (1957).

[23] E. C. Y. Inn and Y. Tanaka, Comparison of recently recorded ozone absorption coefficients in the visible and ultraviolet regions, Conference on Ozone, Armour Research Foundation, Dec. 1956. See also, J. Opt. Soc. Am. 43, 870 (1953).

Washington, June 18, 1958. 